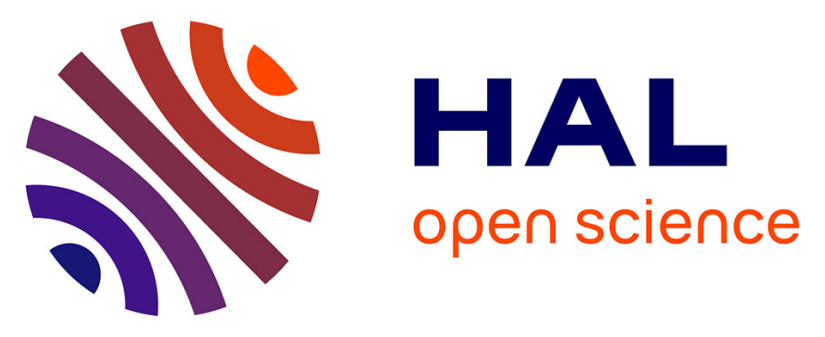

\title{
Reliability of echocardiographic parameters of the systemic right ventricle systolic function: A prospective multicentre study
}

Victor Pommier, Charlene Bredy, Hamouda Abassi, Helena Huguet, Marie-Christine Picot, Sophie Pierard, Agnes Pasquet, Xavier Iriart, Jean-Benoit Thambo, Pascal Amedro

\section{To cite this version:}

Victor Pommier, Charlene Bredy, Hamouda Abassi, Helena Huguet, Marie-Christine Picot, et al.. Reliability of echocardiographic parameters of the systemic right ventricle systolic function: A prospective multicentre study. International Journal of Cardiology Congenital Heart Disease, 2021, pp.100139. 10.1016/j.ijcchd.2021.100139 . hal-03209239

\section{HAL Id: hal-03209239 \\ https://hal.science/hal-03209239}

Submitted on 13 Jun 2021

HAL is a multi-disciplinary open access archive for the deposit and dissemination of scientific research documents, whether they are published or not. The documents may come from teaching and research institutions in France or abroad, or from public or private research centers.
L'archive ouverte pluridisciplinaire HAL, est destinée au dépôt et à la diffusion de documents scientifiques de niveau recherche, publiés ou non, émanant des établissements d'enseignement et de recherche français ou étrangers, des laboratoires publics ou privés. 


\title{
Reliability of echocardiographic parameters of the systemic right ventricle systolic function: A prospective multicentre study
}

\author{
Victor Pommier ${ }^{\mathrm{a}}$, Charlene Bredy ${ }^{\mathrm{a}}$, Hamouda Abassi ${ }^{\mathrm{a}, \mathrm{b}}$, Helena Huguet ${ }^{\mathrm{c}}$, \\ Marie-Christine Picot ${ }^{c, g}$, Sophie Pierard ${ }^{\mathrm{d}}$, Agnes Pasquet ${ }^{\mathrm{d}}$, Xavier Iriart ${ }^{\mathrm{e}, \mathrm{f}}$, \\ Jean-Benoit Thambo ${ }^{\text {e,f }}$, Pascal Amedro ${ }^{\text {a, b, * }}$ \\ ${ }^{a}$ Paediatric and Congenital Cardiology Department, M3C Regional Reference Centre, Montpellier University Hospital, Montpellier, France \\ ${ }^{\mathrm{b}}$ PhyMedExp, CNRS, INSERM, University of Montpellier, 34295, Montpellier, France \\ ${ }^{\mathrm{c}}$ Epidemiology and Clinical Research Department, Montpellier University Medical Centre, Montpellier, France \\ d Congenital Cardiology Department, Cliniques Universitaires Saint-Luc, Brussels, Belgium \\ ${ }^{\mathrm{e}}$ Bordeaux University Hospital (CHU), Department of Pediatric and Adult Congenital Cardiology, Bordeaux, France \\ ${ }^{\mathrm{f}}$ IHU Liryc, Electrophysiology and Heart Modeling Institute, Fondation Bordeaux Université, INSERM, Centre de recherche Cardio-Thoracique de Bordeaux, U1045, \\ Bordeaux, France \\ ${ }^{\mathrm{g}}$ Clinical Investigation Centre, INSERM-CIC 1411, University of Montpellier, Montpellier, France
}

\section{A R T I C L E I N F O}

\section{Keywords:}

Congenital heart disease

Systemic right ventricle

Exercise test

Echocardiography

Oxygen uptake

Software

\begin{abstract}
A B S T R A C T
Background: Systemic right ventricle (RV) is a rare and complex form of congenital heart disease (CHD) with a prognosis related to RV dysfunction and impaired physical capacity. Routine follow-up relies on echocardiography, however the prognostic value of echocardiography parameters remains under debate. Real-life patient follow-up involves different ultrasound systems. We aimed to evaluate echocardiography parameters' reliability in systemic RV, in terms of reproducibility, using vendor-independent software, and in terms prediction of physical capacity impairment.

Methods: Adult patients with D-transposition of the great artery (d-TGA) who underwent atrial switch or with congenitally corrected TGA (cc-TGA) were included in this multicentre prospective study. Current echocardiography parameters were analysed using TomTec-Arena ${ }^{\mathrm{TM}}$ software. Intraclass correlation coefficients (ICC) assessed inter- and intraobserver reliability. Associations between the most reproducible echocardiography parameters and exercise capacity (peak VO2, VE/VCO2 slope) were explored.

Results: A total of 47 patients were included in the study (87\% d-TGA, median age $36.4 \pm 8$ years). Conventional and 2D strain echocardiography parameters indicated the existence of a RV dysfunction (TAPSE $=12.8 \pm 3.1 \mathrm{~mm}$; RV free wall longitudinal 2D strain $=-13.6 \pm 3.9 \%$ ). Good reproducibility (ICC $>0.75$ ) for both intra and interobserver variability was observed in $8 \mathrm{RV}$ echocardiography parameters. Only the TAPSE was significantly associated with peak VO2 $(r=0.4, \mathrm{P}=0.02)$.

Conclusions: In this prospective study mimicking real-life echocardiography follow-up of systemic RV, TAPSE, RV free wall longitudinal 2D strain and peak systolic S wave, were the most reproducible echocardiography parameters. However, only the TAPSE was associated with peak VO2.
\end{abstract}

\section{Introduction}

Among all types of congenital heart diseases (CHD), the systemic right ventricle (RV) represents a rare and complex form, accounting for approximately $10 \%$ of all CHD [1]. In patients with two ventricles, the systemic RV may be observed in two situations: dextro-looped transposition of the great arteries (d-TGA) after atrial switch procedure (Mustard, Senning) and congenitally corrected TGA (cc-TGA) [1-4]. In a normal heart, the RV is a compliant pump providing the low-pressure pulmonary output, whereas the systemic RV provides, by definition, the high-pressure systemic output. However, the RV is not intrinsically adapted to pump against the high-pressure level developed by the

\footnotetext{
* Corresponding author. Paediatric and Congenital Cardiology Department, Arnaud De Villeneuve University Hospital, 371 Avenue du Doyen Giraud, 34295, Montpellier, France.

E-mail address: p-amedro@chu-montpellier.fr (P. Amedro).
} 
systemic circulation, as its fibro-muscular architecture, shape and function, are far different from those of a left ventricle [5-7]. Therefore, most patients with a systemic RV are prone to present with late complications such as heart failure, significant tricuspid regurgitation, or sudden death due to ventricular arrhythmia [1,8-11]. Moreover, patients with a systemic RV will experience a gradual and inexorable decline in their physical capacity, and both maximum oxygen uptake (VO2) and ventilatory efficiency (VE/VCO2 slope), measured during a cardio-pulmonary exercise test (CPET), are associated with disease severity [12-14]. Indeed, these two CPET parameters correlate with prognosis and health-related quality of life in chronic heart failure, including in patients with CHD [14-16], and we recently reported the relevance of CPET for clinical severity assessment in adult patients with a systemic RV [12].

In the routine follow-up, assessment of systemic RV function predominantly relies on transthoracic echocardiography. Cardiac magnetic resonance (CMR) imaging has been considered as the reference method for RV function assessment in such patients [17]. However, compared to echocardiography, CMR is less available, more costly, and more difficult to perform in patients with pacemaker or implantable defibrillator. Moreover, results of studies comparing CMR and echocardiography in systemic RV remain controversial [18-20], and there is currently still a debate on which echocardiography parameter best predicts the patient outcome, especially in terms of physical capacity [21,22]. Furthermore, as opposed to most research studies on cardiac imaging, real-life patient follow-up usually involves examinations performed by different sonographers, on different ultrasound systems.

In this prospective multicentre study, we aimed to evaluate the reliability of echocardiography parameters in a cohort of patients with a systemic RV, in terms of reproducibility, using a vendor-independent software, as well as in terms of prediction of physical capacity impairment.

\section{Methods}

\subsection{Study design and population}

This multicentre cross-sectional study was carried out from June 2017 to April 2019 in three tertiary care CHD centres in France and Belgium (centre 1: Bordeaux University Hospital, France; centre 2: Montpellier University Hospital, France; centre 3: Cliniques Universitaires Saint-Luc, Brussels, Belgium).

Adult patients ( $\geq 18$ years) with a systemic RV were screened during their routine follow-up. Patients with a single ventricle physiology were not eligible (double inlet right ventricle with previous Fontan palliation, and hypoplastic left heart syndrome palliated with the Norwood-Fontan protocol). Therefore, two groups of patients with systemic RV were eligible for the study: d-TGA after atrial switch procedure (Mustard, Senning) and cc-TGA. Patients willing to participate in the study were required to undergo the following examinations in one of the three participating CHD centres: physical examination, electrocardiogram (ECG), transthoracic echocardiography, laboratory testing, and CPET.

\subsection{Clinical and paraclinical parameters}

The following clinical variables were collected: gender, age, weight, height, body mass index (BMI), NYHA functional class, and the type of systemic RV (d-TGA or cc-TGA). The electrocardiographic status (pacemaker, implantable defibrillator), and laboratory parameters (N-terminal pro-brain natriuretic peptide (NT-proBNP)) were collected.

\subsection{CPET parameters}

The main prognosis outcome selected in this study was the exercise capacity evaluated by a CPET, and represented by two major parameters: the peak VO2 and the VE/VCO2 slope.

As in our previous studies using CPET procedures, all centres used a similar cycle ergometer triangular protocol to obtain a homogeneous incremental overall duration between 10 and $15 \mathrm{~min}$ : a 1-min rest; a 3min warm-up (10-20 Watts) in increments of 10,15 , or $20 \mathrm{~W}$ each minute; a pedalling rate of $60-80$ revolutions per minute; a 3-min active recovery $(20 \mathrm{~W})$; and a 2 -min rest $[12,23,24]$. The exercise test was considered as maximal when 3 out of the 4 following criteria were reached: respiratory exchange ratio $(\mathrm{RER}=\mathrm{VCO} 2 / \mathrm{VO} 2) \geq 1.1$, maximum heart rate $>85 \%$ of maximal age-predicted heart rate, limit of the patient's tolerance despite verbal encouragement, plateau of VO2 $\left(\mathrm{VO} 2_{\max }\right)$ despite the increasing exercise intensity. When the oxygen uptake did not reach a plateau, which is very common in adult patients with a systemic RV, the peak VO2 was reported. Peak VO2 values were normalized in a percentage of the predicted $\mathrm{VO} 2_{\max }$ using reference values for cycle ergometer test in the general adult population (named as percent-predicted peak VO2) [25,26]. The ventilatory efficiency, e.g. the VE/VCO2 slope, was determined using linear regression of minute ventilation (VE) and $\mathrm{CO}_{2}$ production $\left(\mathrm{VCO}_{2}\right)[14,27]$.

\subsection{Echocardiography parameters}

In order to reproduce real-life practice, all eligible patients were consecutively enrolled, regardless echogenicity. We did not use any contrast agents. Echocardiography recordings were prospectively stored in DICOM format and offline analyses were performed by an investigator (C.B., senior congenital cardiologist) who was blinded to clinical and CPET data. A second analysis was performed on all recordings, by the same investigator (C.B.) to assess intraobserver reproducibility, and by a second investigator (V.P., fellow) to assess interobserver reproducibility, with no access to the results of first analysis. Echocardiography analyses for 2D strain parameters were performed using TomTec Arena ${ }^{\mathrm{TM}}$ version 40 (TomTec Imaging Systems GmbH, Unterschleissheim, Germany) software, a vendor-independent program that can measure all echocardiographic images stored in DICOM format.

The following RV function parameters were measured, following the recommendations of the American Society of Echocardiography and the European Association of Cardiovascular Imaging [28] and commonly used in systemic RV [18](19): tricuspid annular plane systolic excursion (TAPSE), tricuspid annular diameter, and fractional area change (FAC), from the apical 4-chamber view. Severity of tricuspid regurgitation (TR) was semi-quantitatively graded with colour Doppler method as none, mild, moderate, or severe [29]. Doppler method was used to measure $\mathrm{dP} / \mathrm{dt}$ defined as the time required for the tricuspid valve regurgitation jet to increase velocity from 1 to $3 \mathrm{~m} / \mathrm{s}$, from the ascending limb of the TR continuous-wave Doppler signal. Systemic subaortic velocity time integral (VTI) and the myocardial performance Tei index were obtained using pulsed-wave Doppler. The Tei index was defined as the sum of the isovolumic contraction and the isovolumic relaxation time divided by ejection time [30]. Systolic excursion velocity (S) and isovolumic acceleration (IVA) were measured using pulsed Doppler Tissue Imaging, with Doppler sample volume placed in the tricuspid annulus of the RV free wall [19]. Aortic, mitral and pulmonary regurgitation were semi-quantitatively graded. Inferior vena cava (IVC) diameters (maximum and collapse index) were measured using M-mode echocardiography.

Speckle tracking echocardiography was used to measure RV longitudinal 2D strain, using two different methods from the two available TomTec Arena ${ }^{\mathrm{TM}}$ version 40 software algorithms: one designed for the left ventricle (LV) and the other one designed for the RV. The RV was visualized from the apical 4-chamber view. Using the LV software algorithm, the RV was divided into 3 free wall segments (basal, mid, apical) and 3 interventricular septum segments (basal, mid, apical) (Fig. 2). Using frame rates of 60-80 frames/sec to optimize myocardial deformation analysis, 2D strain analyses were performed for each segment, globally for the RV free wall, globally for the interventricular septum, and globally for the entire RV. As the LV software algorithm is initially dedicated to LV contouring, three markers were manually positioned at 
the RV extremities (apex, tricuspid annulus extremity towards the RV free wall, and tricuspid annulus extremity towards the septum), in order to "force" automatic RV contouring. Using the RV software algorithm, the RV was only divided into 3 free wall segments (basal, mid, apical) (Fig. 3). 2D strain analyses were performed for each segment, and globally for the RV free wall. The RV peak systolic strain was calculated by the software. After positioning 3 markers at the RV extremities (apex, tricuspid annulus extremity towards RV free wall, and tricuspid annulus extremity towards the septum), the RV software algorithm automatically tracked the RV endocardial contour. End systole was defined by aortic valve closure and was automatically recorded by the software. For each software algorithm, tracking was verified and corrected if necessary, by manually adjusting the contour to ensure optimal tracking.

To define altered RV function, we used cut-off values recommended by the American Society of Echocardiography and the European Association of Cardiovascular Imaging: TAPSE $<17 \mathrm{~mm}$, peak $S$ wave $<9.5 \mathrm{~cm} / \mathrm{s}$, FAC $<35 \%$, RV free wall longitudinal 2D strain $<-20 \%$, and Tei index $>0.43$ [28].

\subsection{Formal aspects}

The study was conducted in compliance with the Good Clinical Practices protocol and Declaration of Helsinki principles. The Ethics Committee Nord-Ouest II in France and the UCL Ethics Committee in Belgium approved the study, which was registered on ClinicalTrials.gov (NCT03379831). Informed consent to participate in the study was obtained from all patients.

\subsection{Statistics}

The study population was described using means and standard deviations (SD) for quantitative variables. For qualitative variables, frequencies and their associated percentage were used. The continuous variable distributions were tested with the Shapiro-Wilk statistic. Quantitative variables were compared using Student's t-test when the distribution was Gaussian and using the Mann-Whitney test otherwise. For qualitative variables, groups were compared using the chi-squared test or Fisher's exact test.

To evaluated inter and intra-observer reliability, intraclass correlation coefficients (ICC) were used. As defined by Koo et al., values less than 0.5 , between 0.5 and 0.75 , between 0.75 and 0.9 , and greater than
0.90 were indicative of poor, moderate, good, and excellent reliability, respectively [31].

The association between echocardiography variables and the three CPET parameters (peak VO2, the percent-predicted peak VO2 and the VE/VCO2 slope) was explored by the Pearson correlation coefficient for normal quantitative variables.

The statistical significance was set at 0.05 and analyses were performed using Statistical Analysis Systems Enterprise Guide version 4.3 (SAS Institute, Cary, NC, USA).

\section{Results}

\subsection{Patients}

During the study period, 52 eligible patients were consecutively screened in the three participating centres. Because of poor echocardiographic image quality, five patients were not included (Fig. 1). A total of 47 subjects (mean age $36.4 \pm 8$ years; $66 \%$ male) with a systemic RV were enrolled in the study, in Bordeaux University Hospital $(n=26)$, Saint-Luc University Hospital $(\mathrm{n}=14)$, and Montpellier University Hospital $(n=7)$. More than two-thirds of the patients had undergone Senning atrial switch for d-TGA and only $13 \%$ of the patients had a cc-TGA. Most patients were in NYHA functional class I or II, but had an impaired exercise capacity with a reduced peak VO2 and elevated VE/VCO2 slope (Table 1).

\subsection{General echocardiography parameters}

Echocardiography examinations were performed on two different ultrasound systems, equally divided between EPIQ7 ultrasound (Philips Healthcare) for 24 patients and Acuson SC2000 ultrasound (Siemens Healthcare) for 23 patients.

Conventional and 2D strain echocardiography parameters indicated the existence of a RV dysfunction with a mean TAPSE value of $12.8 \pm 3.1 \mathrm{~mm}$ and a mean RV free wall longitudinal 2D strain value of $-13.6 \pm 3.9 \%$, derived from the RV algorithm. Severe forms of RV dysfunction were not predominant, with severe TR observed in only 4 patients and baffle obstruction in only 2 patients. Overall, significant additional anatomic lesions such as LV outflow tract obstruction, pulmonary stenosis, and baffle leaks, were not observed. After atrial switch repair, baffle stenosis was reported for only two out of 41 patients

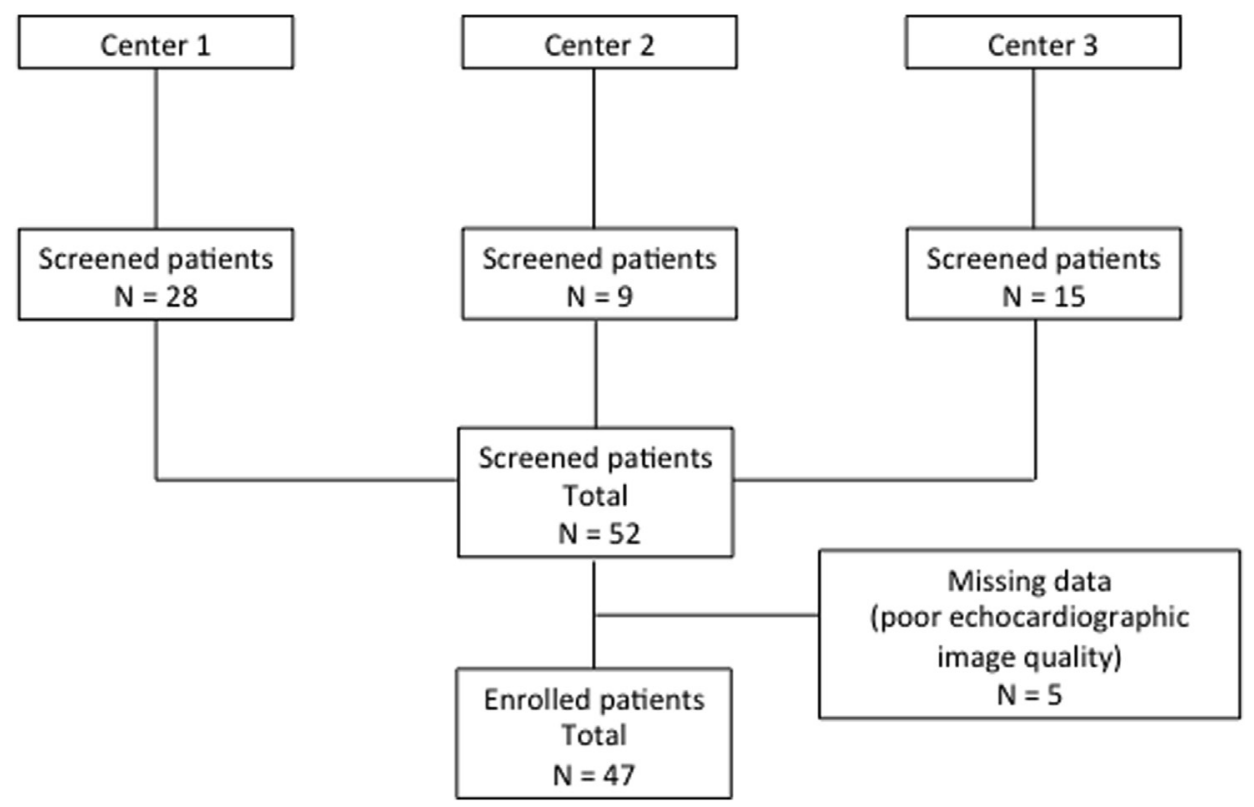

Fig. 1. Flow chart. 

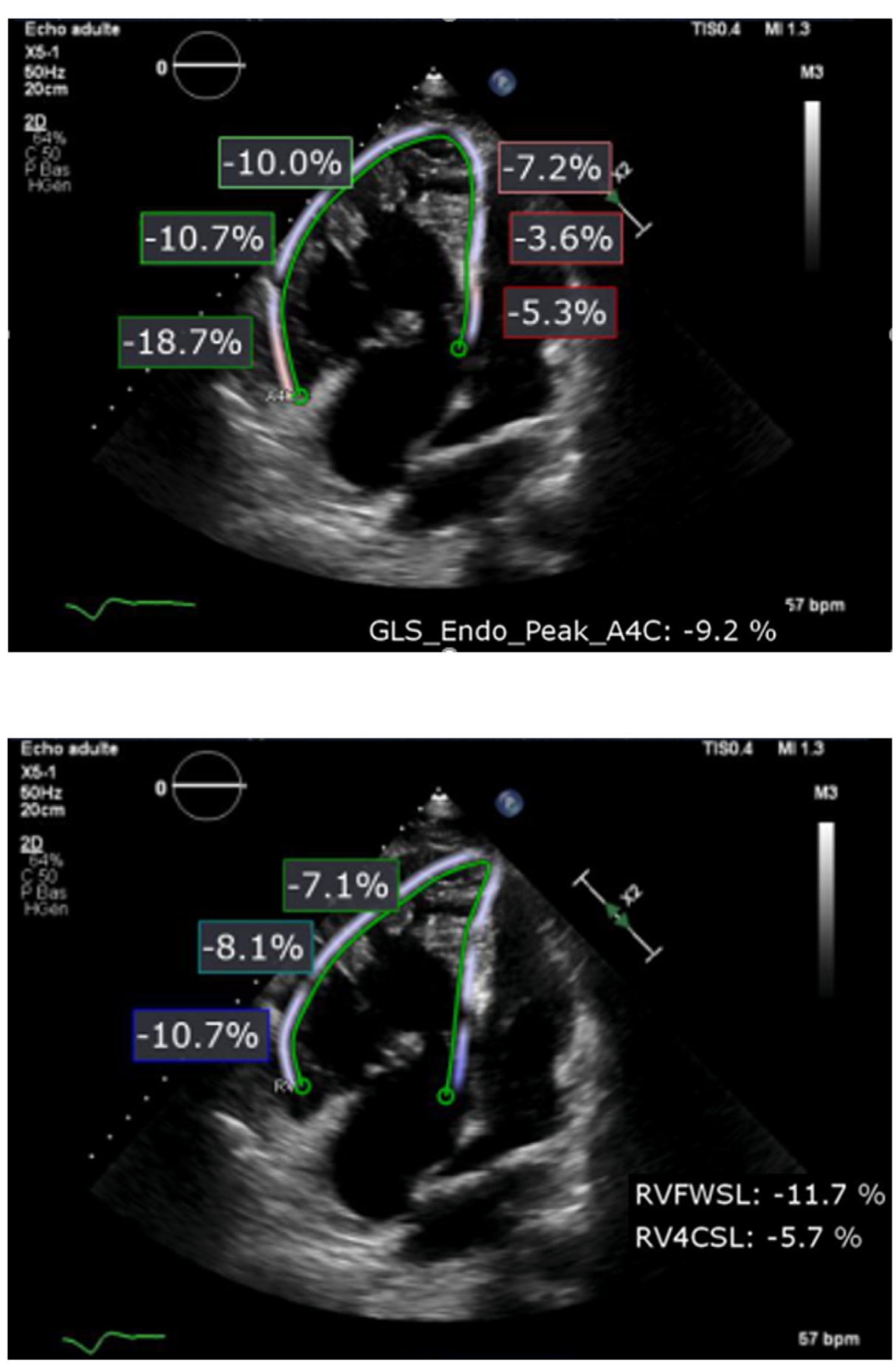

Fig. 2. Longitudinal RV 2D strain measured with LV software algorithm.

Legend: green frames, free wall segment (from top to bottom): apical, mid, basal segments; red frames, septal segment (from top to bottom): apical, mid, basal. GLS_Endo_Peak_A4C, right ventricle global longitudinal 2D strain using LV software algorithm. (For interpretation of the references to colour in this figure legend, the reader is referred to the Web version of this article.)
(Table 2).

\subsection{Reproducibility of $R V$ echocardiography parameters}

Intraobserver reproducibility was good to excellent for nearly all RV conventional and 2D strain echocardiography parameters (all ICCs $>0.75, \mathrm{P}<0.001$ ). Only the Tei index and the apical septal 2D strain using $\mathrm{RV}$ strain software algorithm showed a moderate reproducibility (ICCs were 0.60 and 0.70 respectively, $\mathrm{P}<0.001$ ).

Interobserver reproducibility was good to excellent (ICCs $>0.75$, $\mathrm{P}<0.001$ ) for three conventional parameters (TAPSE, peak systolic $\mathrm{S}$ wave and $\mathrm{dP} / \mathrm{dt}$ ). Very poor reproducibility was observed for the Tei index and the IVA (ICCs $<0.10$ ). Interobserver reproducibility was
Fig. 3. Longitudinal RV 2D strain measured with RV software algorithm.

Legend: deep blue segment, basal free wall segment; light blue segment, mid free wall segment; green segment, apical free wall segment; RVFWSL, right ventricle free wall strain lateral; RV4CSL, right ventricle global longitudinal $2 \mathrm{D}$ strain using $\mathrm{RV}$ software algorithm. (For interpretation of the references to colour in this figure legend, the reader is referred to the Web version of this article.) 
Table 1

Study population.

\begin{tabular}{|c|c|c|c|}
\hline Variables & & & \\
\hline Age (years) & & & $36.4 \pm 8.0$ \\
\hline \multirow[t]{2}{*}{ Gender } & & Male & $31(66)$ \\
\hline & & Female & $16(34)$ \\
\hline Height (cm) & & & $171.4 \pm 8.4$ \\
\hline Weight $(k g)$ & & & $69.8 \pm 17.3$ \\
\hline \multirow[t]{3}{*}{ Type of systemic RV } & d-TGA & Senning & $32(68)$ \\
\hline & ccTGA & Mustard & 9 (19) \\
\hline & & & $6(13)$ \\
\hline \multirow[t]{4}{*}{ NYHA functional class } & & I & $31(66)$ \\
\hline & & II & $14(30)$ \\
\hline & & III & $2(4)$ \\
\hline & & IV & $0(0)$ \\
\hline NT-pro-BNP $(p g / m L)$ & & & $86.3 \pm 57.8$ \\
\hline Peak VO2 $(m L / K g / m i n)$ & & & $21.6 \pm 7.3$ \\
\hline Percent-predict VO2 (\%) & & & $56.5 \pm 16.8$ \\
\hline VE/VCO2 slope & & & $33.9 \pm 7.2$ \\
\hline
\end{tabular}

Legend: Values are mean \pm standard deviation (SD) or N (\%). NYHA, New York Heart Association; RV, right ventricle; VO2, oxygen uptake; VE/VCO2 slope, ventilatory efficiency.

\subsection{Correlation between most reproducible echocardiography $R V$ parameters and physical capacity}

When measuring the association between those eight most reproducible RV echocardiography parameters and the CPET parameters, we found that only the TAPSE presented a significant correlation with peak VO2 $(r=0.40, P=0.02)$. The association between RV longitudinal 2D strain using RV speckle tracking software algorithm and peak VO2 was moderate and did not reach statistical significance $(\mathrm{r}=0.23, \mathrm{P}=0.14)$. No association was found between any RV echocardiography parameter and the VE/VCO2 slope (Table 4).

\section{Discussion}

In this prospective multicentre study, from a cohort of adult patients with a systemic RV, good reproducibility was found in most conventional and 2D strain RV echocardiography parameters. In order to best match the reality of clinical follow-up, our study analysed echocardiography examinations performed by different sonographers, on different ultrasound systems, and used, for the first time in this population, the TomTec-Arena ${ }^{\mathrm{TM}}$ vendor-independent software for 2D strain analysis.

Among all echocardiography parameters tested in this study, the

Table 2

Echocardiography parameters.

\begin{tabular}{|c|c|c|c|}
\hline \multicolumn{4}{|l|}{ Echocardiography parameters } \\
\hline TAPSE (mm) & & & $12.8 \pm 3.1$ \\
\hline Tricuspid annulus diameter (mm) & & & $38.6 \pm 6.8$ \\
\hline RV fractional area change (\%) & & & $33.8 \pm 7.8$ \\
\hline \multirow[t]{4}{*}{ Tricuspid regurgitation } & & None & $5(11)$ \\
\hline & & Mild & $29(61)$ \\
\hline & & Moderate & 9 (19) \\
\hline & & Severe & $4(9)$ \\
\hline Tricuspid dP/dt $(\mathrm{mmHg} / \mathrm{s})$ & & & $838.4 \pm 326.8$ \\
\hline Systemic (subaortic) VTI (cm) & & & $17.3 \pm 4.5$ \\
\hline Tei index & & & $0.31 \pm 0.13$ \\
\hline Peak S wave $(\mathrm{cm} / \mathrm{sec})$ & & & $7.12 \pm 1.84$ \\
\hline $\operatorname{IVA}\left(m / s^{2}\right)$ & & & $1.89 \pm 0.47$ \\
\hline IVC maximum expiration diameter ( $\mathrm{mm}$ ) & & & $16.6 \pm 2.8$ \\
\hline IVC collapse index & & & $0.58 \pm 0.16$ \\
\hline \multirow[t]{4}{*}{ Aortic regurgitation } & & None & $38(81)$ \\
\hline & & Mild & $8(17)$ \\
\hline & & Moderate & $0(0)$ \\
\hline & & Severe & $1(2)$ \\
\hline \multirow[t]{4}{*}{ Mitral regurgitation } & & None & $42(89)$ \\
\hline & & Mild & $4(9)$ \\
\hline & & Moderate & $1(2)$ \\
\hline & & Severe & $0(0)$ \\
\hline \multirow[t]{4}{*}{ Pulmonary regurgitation } & & None & $27(57)$ \\
\hline & & Mild & $20(20)$ \\
\hline & & Moderate & $0(0)$ \\
\hline & & Severe & $0(0)$ \\
\hline \multirow[t]{5}{*}{ RV longitudinal 2D strain using RV software algorithm } & Free wall & Basal & $-14.56 \pm 4.45$ \\
\hline & & Mid & $-13.29 \pm 3.90$ \\
\hline & & Apical & $-12.60 \pm 3.58$ \\
\hline & & Global & $-13.58 \pm 3.94$ \\
\hline & RV global longitudinal strain & & $-11.64 \pm 3.09$ \\
\hline \multirow[t]{9}{*}{ RV longitudinal 2D strain using LV software algorithm } & Free wall & Basal & $-18.58 \pm 7.31$ \\
\hline & & Mid & $-13.63 \pm 5.14$ \\
\hline & & Apical & $-11.83 \pm 5.73$ \\
\hline & & Global & $-14.68 \pm 4.37$ \\
\hline & Septum & Basal & $-9.09 \pm 5.61$ \\
\hline & & Mid & $-10.87 \pm 4.73$ \\
\hline & & Apical & $-10.85 \pm 4.66$ \\
\hline & & Global & $-10.27 \pm 3.65$ \\
\hline & RV global longitudinal strain & & $-12.41 \pm 3.47$ \\
\hline \multirow[t]{2}{*}{ Baffle analysis } & & Obstruction & $2(5)$ \\
\hline & & No obstruction & $39(95)$ \\
\hline
\end{tabular}

Legend: Values are mean \pm standard deviation (SD) or N (\%). LV, left ventricle; RV, right ventricle; TAPSE = tricuspid annular plane systolic excursion; TR, tricuspid regurgitation; MPI, myocardial performance index; IVA, isovolumic acceleration; TDI, tissue doppler imaging; VTI, velocity time integral. 
Table 3

Reproducibility of RV echocardiography parameters.

\begin{tabular}{|c|c|c|c|c|c|c|c|c|}
\hline \multirow[t]{2}{*}{ RV echocardiography parameters } & & & \multicolumn{3}{|c|}{ Intraobserver variability } & \multicolumn{3}{|c|}{ Interobserver variability } \\
\hline & & & ICC & {$[95 \% \mathrm{CI}]$} & P-value & ICC & {$[95 \% \mathrm{CI}]$} & P-value \\
\hline \multicolumn{3}{|l|}{ TAPSE } & 0.97 & {$[0.93 ; 0.98]$} & $<0.001$ & 0.86 & {$[0.75 ; 0.93]$} & $<0.001$ \\
\hline \multicolumn{3}{|l|}{ Tricuspid annulus diameter } & 0.96 & {$[0.93 ; 0.98]$} & $<0.001$ & 0.67 & {$[0.47 ; 0.81]$} & $<0.001$ \\
\hline \multicolumn{3}{|l|}{ RV fractional area change } & 0.93 & {$[0.88 ; 0.96]$} & $<0.001$ & 0.17 & {$[-0.14 ; 0.45]$} & 0.14 \\
\hline \multicolumn{3}{|l|}{ Tricuspid dP/dt } & 0.98 & {$[0.95 ; 0.99]$} & $<0.001$ & 0.77 & {$[0.49 ; 0.91]$} & $<0.001$ \\
\hline \multicolumn{3}{|l|}{ Systemic (subaortic) VTI } & 0.97 & {$[0.92 ; 0.98]$} & $<0.001$ & 0.56 & {$[0.24 ; 0.78]$} & $<0.001$ \\
\hline \multicolumn{3}{|l|}{ Tei index (Doppler) } & 0.60 & {$[0.20 ; 0.83]$} & $<0.01$ & 0.09 & {$[-0.47 ; 0.61]$} & 0.38 \\
\hline \multicolumn{3}{|l|}{ Peak S wave (TDI) } & 0.92 & {$[0.85 ; 0.96]$} & $<0.001$ & 0.90 & {$[0.79 ; 0.95]$} & $<0.001$ \\
\hline \multicolumn{3}{|l|}{ IVA (TDI) } & 0.81 & {$[0.63 ; 0.90]$} & $<0.001$ & 0 & {$[-0.39 ; 0.37]$} & 0.53 \\
\hline \multicolumn{3}{|l|}{ IVC maximum diameter (expiration) } & 0.85 & {$[0.72 ; 0.92]$} & $<0.001$ & 0.65 & {$[0.38 ; 0.82]$} & $<0.001$ \\
\hline \multicolumn{3}{|l|}{ IVC collapse index } & 0.71 & {$[0.44 ; 0.86]$} & $<0.001$ & 0.35 & {$[-0.07 ; 0.67]$} & 0.05 \\
\hline \multirow{5}{*}{$\begin{array}{l}\text { RV longitudinal 2D strain using RV speckle tracking software } \\
\text { algorithm }\end{array}$} & \multirow[t]{4}{*}{ Free wall } & Basal & 0.95 & {$[0.91 ; 0.97]$} & $<0.001$ & 0.82 & {$[0.69 ; 0.90]$} & $<0.001$ \\
\hline & & Mid & 0.97 & {$[0.94 ; 0.98]$} & $<0.001$ & 0.78 & {$[0.64 ; 0.87]$} & $<0.001$ \\
\hline & & Apical & 0.94 & {$[0.90 ; 0.97]$} & $<0.001$ & 0.76 & {$[0.60 ; 0.86]$} & $<0.001$ \\
\hline & & Global & 0.98 & {$[0.97 ; 0.99]$} & $<0.001$ & 0.79 & {$[0.64 ; 0.88]$} & $<0.001$ \\
\hline & $\begin{array}{l}\text { RV global longitudinal } \\
\text { strain }\end{array}$ & & 0.91 & {$[0.84 ; 0.95]$} & $<0.001$ & 0.70 & {$[0.52 ; 0.83]$} & $<0.001$ \\
\hline \multirow{9}{*}{$\begin{array}{l}\text { RV longitudinal 2D strain using LV speckle tracking software } \\
\text { algorithm }\end{array}$} & \multirow[t]{4}{*}{ Free wall } & Basal & 0.92 & {$[0.86 ; 0.95]$} & $<0.001$ & 0.73 & {$[0.55 ; 0.84]$} & $<0.001$ \\
\hline & & Mid & 0.80 & {$[0.66 ; 0.88]$} & $<0.001$ & 0.49 & {$[0.24 ; 0.69]$} & $<0.001$ \\
\hline & & Apical & 0.88 & {$[0.79 ; 0.93]$} & $<0.001$ & 0.59 & {$[0.35 ; 0.75]$} & $<0.001$ \\
\hline & & Global & 0.92 & {$[0.85 ; 0.95]$} & $<0.001$ & 0.78 & {$[0.63 ; 0.87]$} & $<0.001$ \\
\hline & \multirow[t]{4}{*}{ Septum } & Basal & 0.79 & {$[0.64 ; 0.88]$} & $<0.001$ & 0.50 & {$[0.25 ; 0.69]$} & $<0.001$ \\
\hline & & Mid & 0.92 & {$[0.87 ; 0.96]$} & $<0.001$ & 0.70 & {$[0.51 ; 0.82]$} & $<0.001$ \\
\hline & & Apical & 0.70 & {$[0.51 ; 0.82]$} & $<0.001$ & 0.58 & {$[0.34 ; 0.74]$} & $<0.001$ \\
\hline & & Global & 0.91 & {$[0.83 ; 0.95]$} & $<0.001$ & 0.59 & {$[0.36 ; 0.75]$} & $<0.001$ \\
\hline & $\begin{array}{l}\text { RV global longitudinal } \\
\text { strain }\end{array}$ & & 0.97 & {$[0.95 ; 0.98]$} & $<0.001$ & 0.25 & {$[-0.05 ; 0.50]$} & 0.05 \\
\hline
\end{tabular}

Legend: ICC, intraclass correlation coefficient; CI, confidence interval; IVA, isovolumic acceleration; IVC, inferior vena cava; LV, left ventricle; RV, right ventricle; TAPSE, tricuspid annular plane systolic excursion; TDI, tissue Doppler imaging; Tei index, myocardial performance index; VTI, velocity time integral.

Table 4

Correlation between most reproducible echocardiography RV parameters and physical capacity.

\begin{tabular}{|c|c|c|c|c|c|c|c|c|}
\hline & & & \multicolumn{2}{|c|}{ Peak VO2 } & \multicolumn{2}{|c|}{ Percent-predict peak VO2 } & \multicolumn{2}{|c|}{ VE/VCO2 slope } \\
\hline & & & $\mathrm{r}$ & P-value & $\mathrm{r}$ & P-value & $\mathrm{r}$ & P-value \\
\hline TAPSE & & & 0.40 & 0.02 & 0.16 & 0.37 & -0.11 & 0.56 \\
\hline \multirow[t]{4}{*}{ RV longitudinal 2D strain using RV software algorithm } & Free wall & Apical & 0.23 & 0.14 & 0.26 & 0.11 & -0.08 & 0.63 \\
\hline & & Global & 0.19 & 0.22 & 0.21 & 0.20 & 0.01 & 0.96 \\
\hline & & Basal & 0.19 & 0.22 & 0.19 & 0.25 & 0.09 & 0.60 \\
\hline & & Medial & 0.17 & 0.30 & 0.20 & 0.21 & -0.05 & 0.75 \\
\hline RV longitudinal 2D strain using LV software algorithm & Free Wall & Global & 0.13 & 0.40 & 0.13 & 0.41 & -0.10 & 0.54 \\
\hline Peak $S$ wave & & & -0.07 & 0.73 & 0.23 & 0.24 & -0.28 & 0.16 \\
\hline Tricuspid dP/dt & & & -0.02 & 0.93 & -0.06 & 0.80 & -0.35 & 0.13 \\
\hline
\end{tabular}

Legend: TAPSE, tricuspid annular plane systolic excursion; LV, left ventricle; RV, right ventricle; TDI, tissue Doppler imaging.

TAPSE appeared to be the only predictor of physical capacity in systemic $\mathrm{RV}$, with very low intra and inter-observer variability (ICC of 0.97 and 0.86 , respectively). Indeed, the TAPSE is easily measurable in M-mode from the apical 4-chamber view, even if image quality is mediocre or endocardial border recognition is difficult, as opposed to strain and FAC measures [6,32]. Moreover, in our study, the TAPSE was significantly correlated with peak oxygen uptake, which is considered as a major prognosis parameter in systemic RV [13]. This is in line with the recent study from Gavotto et al., showing an association between TAPSE and percent-predict peak VO2 $(r=0.40 ; \mathrm{P}<0.001)$ from a cohort of 111 patients with a systemic RV [12]. Similarly, Winter et al. reported that TAPSE was significantly associated with peak VO2, NYHA functional class and NT-proBNP in a cohort of 50 patients [33]. As in our study, the TAPSE was the only echocardiography parameter correlating with physical capacity. Moreover, Lissin, et al. found a correlation between TAPSE and CMR assessments of systemic RV function $(r=0.66, P=0.01)$ [18]. More generally, in many pathologies affecting the RV, the TAPSE has shown some interest in terms of RV function follow-up or even as a prognosis biomarker, such as in pulmonary arterial hypertension [34], or pulmonary embolism [35]. In the natural history of systemic RV, Pettersen et al. have described the existing shift from longitudinal myocardial fibres to circumferential myocardial fibres [7]. As the TAPSE reflects the RV longitudinal contraction developed by longitudinal myocardial fibres, it therefore correlates with systolic dysfunction in systemic RV. The normal values for TAPSE in systemic RV are known to be lower than in normal sub-pulmonary RV [36]. Therefore, decrease in longitudinal function, which TAPSE reflects, could be to some degree an adaptive process and not a real impairment of RV function.

Then, our study found that reproducibility of RV longitudinal 2D strain was good, globally and for each segment. Moreover, using for the first time both LV and RV TomTec-Arena ${ }^{\mathrm{TM}}$ software algorithms in systemic RV, we observed the lowest variability for the RV free wall global longitudinal 2D strain with the RV software algorithm (ICC of 0.98 and 0.79 for intra and inter-observer variability, respectively). The systemic $\mathrm{RV}$ has a function similar to a $\mathrm{LV}$, however its shape remains close to a normal sub-pulmonary RV. Therefore, the RV software algorithm from TomTec-Arena ${ }^{\mathrm{TM}}$ appeared to be well adapted to 2D strain analyses in systemic RV. The recent study from Ladouceur et al. on a similar 
population found good interobserver reproducibility (ICC of 0.93) of RV global longitudinal 2D strain using LV software algorithm [21]. However, in this retrospective study, echocardiography examinations were performed by a single examiner, on a single ultrasound system and off-line analyses were performed on a vendor-dependant software (EchoPAC, General Electric Healthcare).

Unfortunately, despite this good reproducibility, the association between RV free wall global longitudinal 2D strain (using the RV software algorithm) and peak VO2 in our study did not reach statistical significance $(r=0.23 ; P=0.14)$, probably because of a low sample size. Indeed, previous studies found a significant association, in patients with systemic $\mathrm{RV}$, between RV free wall global longitudinal 2D strain and peak VO2 $(\mathrm{r}=0.42 ; \mathrm{P}=0.007)$ [21], clinical events [37] or RV ejection fraction [38, 39].

Both TAPSE and RV free wall longitudinal 2D strain reflect RV longitudinal function and both proved to be reproducible according to our study results. Nevertheless, only the TAPSE correlated with peak VO2. In various pathologies affecting the RV, such as pulmonary hypertension, TAPSE has been the most popular measure used as a surrogate for RV longitudinal systolic function, with a high proven prognostic significance [40]. Despite being a load-dependent and angle-dependent parameter reflecting mainly the lateral wall longitudinal motion, the TAPSE's widespread use is also due to its simplicity of acquisition, and its high reproducibility with low inter-operator variability [41]. Speckle tracking echocardiography has more recently emerged and shown promising RV contractility evaluation results. Although regional and global 2D strains are load and angle-dependent measurements [42], several clinical studies in pulmonary hypertension have shown their prognostic value with an acceptable inter and intraobserver variability [43]. In systemic RV, the prognostic value of $2 \mathrm{D}$ strain may be limited by the great heterogeneity in terms of RV shape.

Finally, our study provided original data on the variability of all the remaining RV echocardiography parameters. Three variables had a good reproducibility (tricuspid $\mathrm{dP} / \mathrm{dt}$, peak systolic $\mathrm{S}$ wave, and IVC expiration diameter), but were not correlated with any CPET data. In particular, the peak systolic $S$ wave was one of the most reproducible parameters in this study, considering both inter and intra observer variability (ICCs of 0.92 and 0.90 , respectively). This remains controversial in the literature. Indeed, the peak systolic $S$ wave has been correlated with RV dysfunction [19] or percent-predict peak VO2 in systemic RV [12]. Conversely, three variables (FAC, Tei index and IVA) have shown poor reproducibility in our study. Yet, some previous studies have observed an association between those parameters and CPET or RV dysfunction, however none has investigated their reproducibility. For instance, Kalogeropoulos et al. reported a correlation between FAC and RV ejection fraction assessed by CMR in systemic RV [37]. Guidelines from the American Society of Echography (ASE) have commented on the interest of FAC in RV function assessment [44], but one of the two provided references found only a weak correlation between FAC and RV ejection fraction assessed by CMR [45]. Measuring FAC may be challenging as the RV contouring beneath the trabeculations is difficult and requires a good apical-4C view to see the apex, unlike the TAPSE. Reports on the Tei index remain controversial, some studies claiming its interest in pulmonary arterial hypertension $[30,46]$, and others showing the absence of any correlation with clinical events $[19,37]$. The reliability of IVA analysis had not been previously reported in systemic RV, to our knowledge. This parameter has shown some interest for RV assessment before cardiac surgery [47], however no association with clinical events has been established in previous studies [37].

\subsection{Study limitations}

The low sample size may have resulted in the lack of statistical significance in the association between some echocardiography parameters and CPET parameters, especially for RV longitudinal 2D strain. Moreover, we plan to carry out a larger prospective study to identify TAPSE cut-off values to predict RV dysfunction in systemic RV.

\section{Conclusions}

This prospective study attempted to reflect real-life follow-up of patients with systemic RV, involving different sonographers and different ultrasound systems. We found that the TAPSE, the global RV free wall longitudinal 2D strain, and the peak systolic $S$ wave were the most reproducible echocardiographic parameters. However, only the TAPSE was associated with peak VO2. Further studies should determine whether the TAPSE could be used as a predictor of prognosis.

\section{ClinicalTrials number}

\section{NCT03379831.}

\section{Acknowledgement of grant support}

This work was funded by Montpellier University Hospital Clinical Research Program (AOI-UF8745). XI and JBT were supported by the French Government as part of the "Investments of the future" program managed by the ANR, National Research Agency [Grant reference ANR10-IAHU-04].

\section{Declaration of competing interest}

The authors declare that there is no conflict of interest.

\section{Acknowledgments}

We thank our patients for their participation in the study and our CPET laboratory technicians for their work.

\section{References}

[1] Brida M, Diller G-P, Gatzoulis MA. Systemic right ventricle in adults with congenital heart disease: anatomic and phenotypic spectrum and current approach to management. Circulation 30 janv 2018;137(5):508-18.

[2] Meisner H, Feder E, Struck E, Yueh HH, Paek SU, Sebening F. Mustard versus Senning procedure: a comparison of primary atrial inversion procedures in 108 patients with transposition of the great arteries. Herz août 1982;7(4):259-66.

[3] Senning A. Surgical correction of transposition of the great vessels. Surgery juin 1959;45(6):966-80.

[4] Mustard WT. Successful two-stage correction OF transposition OF the great vessels. Surg Mars 1964;55:469-72.

[5] Andrade L, Carazo M, Wu F, Kim Y, Wilson W. Mechanisms for heart failure in systemic right ventricle. Heart Fail Rev juill 2020;25(4):599-607.

[6] François Haddad, Hunt Sharon A, Rosenthal David N, Murphy Daniel J. Right ventricular function in cardiovascular disease, Part I. Circulation 18 mars 2008; 117(11):1436-48.

[7] Pettersen E, Helle-Valle T, Edvardsen T, Lindberg H, Smith H-J, Smevik B, et al. Contraction pattern of the systemic right ventricle: shift from longitudinal to circumferential shortening and absent global ventricular torsion. J Am Coll Cardiol 26 juin 2007;49(25):2450-6.

[8] Rooshesselink J. Decline in ventricular function and clinical condition after mustard repair for transposition of the great arteries (a prospective study of 22-29 years). Eur Heart J juill 2004;25(14):1264-70.

[9] Helbing WA, Hansen B, Ottenkamp J, Rohmer J, Chin JG, Brom AG, et al. Long-term results of atrial correction for transposition of the great arteries. Comparison of Mustard and Senning operations. J Thorac Cardiovasc Surg août 1994;108(2): 363-72.

[10] Prieto LR, Hordof AJ, Secic M, Rosenbaum MS, Gersony WM. Progressive tricuspid valve disease in patients with congenitally corrected transposition of the great arteries. Circulation 8 sept 1998;98(10):997-1005.

[11] Shiina Y, Inai K, Takahashi T, Taniguchi K, Watanabe E, Fukushima K, et al. Interand intra-ventricular dyssynchrony in the systemic right ventricle is a surrogate marker of major cardiac events in mildly symptomatic patients. Heart Vessels sept 2018;33(9):1086-93.

[12] Gavotto A, Abassi H, Rola M, Serrand C, Picot M-C, Iriart X, et al. Factors associated with exercise capacity in patients with a systemic right ventricle. Int J Cardiol oct 2019;292:230-5.

[13] Shafer KM, Janssen L, Carrick-Ranson G, Rahmani S, Palmer D, Fujimoto N, et al. Cardiovascular response to exercise training in the systemic right ventricle of adults with transposition of the great arteries: CV response to exercise in systemic right ventricles. J Physiol 1 juin 2015;593(11):2447-58. 
[14] Gavotto A, Huguet H, Picot M-C, Guillaumont S, Matecki S, Amedro P. The VE/ VCO2 slope: a useful tool to evaluate the physiological status of children with congenital heart disease. J Appl Physiol 19852020 Nov 1;129(5):1102-10.

[15] Diller G-P, Dimopoulos K, Okonko D, Li W, Babu-Narayan SV, Broberg CS, et al. Exercise intolerance in adult congenital heart disease: comparative severity, correlates, and prognostic implication. Circulation 9 août 2005;112(6):828-35.

[16] Myers J, Arena R, Dewey F, Bensimhon D, Abella J, Hsu L, et al. A cardiopulmonary exercise testing score for predicting outcomes in patients with heart failure. Am Heart J déc 2008;156(6):1177-83.

[17] Bonello B, Kilner PJ. Review of the role of cardiovascular magnetic resonance in congenital heart disease, with a focus on right ventricle assessment. Arch Cardiovasc Dis 1 nov 2012;105(11):605-13.

[18] Lissin LW, Li W, Murphy DJ, Hornung T, Swan L, Mullen M, et al. Comparison of transthoracic echocardiography versus cardiovascular magnetic resonance imaging for the assessment of ventricular function in adults after atrial switch procedures for complete transposition of the great arteries. Am J Cardiol 1 mars 2004;93(5):654-7.

[19] Iriart X, Roubertie F, Jalal Z, Thambo J-B. Quantification of systemic right ventricle by echocardiography. Arch Cardiovasc Dis févr 2016;109(2):120-7.

[20] Samyn MM, Yan K, Masterson C, Goot BH, Saudek D, Lavoie J, et al. Echocardiography vs cardiac magnetic resonance imaging assessment of the systemic right ventricle for patients with d-transposition of the great arteries status post atrial switch. Congenit Heart Dis nov 2019;14(6):1138-48.

[21] Ladouceur M, Redheuil A, Soulat G, Delclaux C, Azizi M, Patel M, et al. Longitudinal strain of systemic right ventricle correlates with exercise capacity in adult with transposition of the great arteries after atrial switch. Int J Cardiol août 2016;217: 28-34.

[22] Iriart X, Le Quellenec S, Pillois X, Jaussaud J, Jalal Z, Roubertie F, et al. Heart rate response during exercise predicts exercise tolerance in adults with transposition of the great arteries and atrial switch operation. Int J Cardiol janv 2020;299:116-22.

[23] Gavotto A, Vandenberghe D, Abassi H, Huguet H, Macioce V, Picot M-C, et al. Oxygen uptake efficiency slope: a reliable surrogate parameter for exercise capacity in healthy and cardiac children? Arch Dis Child 30 juill 2020.

[24] Amedro P, Gavotto A, Bredy C, Guillaumont S. [Cardiac rehabilitation for children and adults with congenital heart disease]. Presse Medicale Paris Fr 1983;46(5): 530-7. mai 2017.

[25] Guazzi M, Adams V, Conraads V, Halle M, Mezzani A, Vanhees L, et al. Clinical recommendations for cardiopulmonary exercise testing data assessment in specific patient populations. Circulation 30 oct 2012;126(18):2261-74.

[26] Jones NL, Makrides L, Hitchcock C, Chypchar T, McCartney N. Normal standards for an incremental progressive cycle ergometer test. Am Rev Respir Dis mai 1985; 131(5):700-8.

[27] Paolillo S, Veglia F, Salvioni E, Corrà U, Piepoli M, Lagioia R, et al. Heart failure prognosis over time: how the prognostic role of oxygen consumption and ventilatory efficiency during exercise has changed in the last 20 years: $\mathrm{VO}_{2}$ and VE/ VCO $_{2}$ values in HF prognosis over time. Eur J Heart Fail févr 2019;21(2):208-17.

[28] Lang RM, Badano LP, Mor-Avi V, Afilalo J, Armstrong A, Ernande L, et al. Recommendations for cardiac chamber quantification by echocardiography in adults: an update from the American society of echocardiography and the European association of cardiovascular imaging. J Am Soc Echocardiogr janv 2015;28(1): 1-39. e14.

[29] Lewis M, Ginns J, Rosenbaum M. Is systemic right ventricular function by cardiac MRI related to the degree of tricuspid regurgitation in congenitally corrected transposition of the great arteries? Int J Cardiol juill 2014;174(3):586-9.

[30] Tei C, Ling LH, Hodge DO, Bailey KR, Oh JK, Rodeheffer RJ, et al. New index of combined systolic and diastolic myocardial performance: a simple and reproducible measure of cardiac function-a study in normals and dilated cardiomyopathy. J Cardiol déc 1995;26(6):357-66.

[31] Koo TK, Li MY. A guideline of selecting and reporting intraclass correlation coefficients for reliability research. J Chiropr Med juin 2016;15(2):155-63.

[32] Leung DY, Ng ACT. Emerging clinical role of strain imaging in echocardiography. Heart lung circ mars 2010;19(3):161-74.

[33] Winter MM, Bouma BJ, Hardziyenka M, De Bruin-Bon RHACM, Tan HL, Konings TC, et al. Echocardiographic determinants of the clinical condition in patients with a systemic right ventricle: echocardiography and the systemic right ventricle. Echocardiography nov 2010;27(10):1247-55.

[34] Tello K, Axmann J, Ghofrani HA, Naeije R, Narcin N, Rieth A, et al. Relevance of the TAPSE/PASP ratio in pulmonary arterial hypertension. Int J Cardiol sept 2018;266: 229-35.

[35] Mahfoudhi H, Chenik S, Haggui A, Dahmani R, Mastouri M, Lahidheb D, et al. Fonction ventriculaire droite après un premier épisode d'embolie pulmonaire : apport du strain 2D. Ann Cardiol Angéiologie 1 mai 2020;69(3):115-9.

[36] Morcos M, Kilner PJ, Sahn DJ, Litt HI, Valsangiacomo-Buechel ER, Sheehan FH. Comparison of systemic right ventricular function in transposition of the great arteries after atrial switch and congenitally corrected transposition of the great arteries. Int J Cardiovasc Imaging déc 2017;33(12):1993-2001.

[37] Kalogeropoulos AP, Deka A, Border W, Pernetz MA, Georgiopoulou VV, Kiani J, et al. Right ventricular function with standard and speckle-tracking echocardiography and clinical events in adults with D-transposition of the great arteries post atrial switch. J Am Soc Echocardiogr 1 mars 2012;25(3):304-12.

[38] Lipczyńska M, Szymański P, Kumor M, Klisiewicz A, Ł Mazurkiewicz, Hoffman P. Global longitudinal strain may identify preserved systolic function of the systemic right ventricle. Can J Cardiol juin 2015;31(6):760-6.

[39] Woudstra OI, van Dissel AC, van der Bom T, de Bruin-Bon RHACM, van Melle JP, van Dijk APJ, et al. Myocardial deformation in the systemic right ventricle: strain imaging improves prediction of the failing heart. Can J Cardiol déc 2019. S0828282X19315272.

[40] Miotti C, Papa S, Manzi G, Scoccia G, Luongo F, Toto F, et al. The growing role of echocardiography in pulmonary arterial hypertension risk stratification: the missing piece. J Clin Med 6 févr 2021;10(4):619.

[41] Jones N, Burns AT, Prior DL. Echocardiographic assessment of the right ventricle-state of the art. Heart Lung Circ sept 2019;28(9):1339-50.

[42] Wright L, Negishi K, Dwyer N, Wahi S, Marwick TH. Afterload dependence of right ventricular myocardial strain. J Am Soc Echocardiogr juill 2017;30(7):676-684.e1.

[43] Badagliacca R, Pezzuto B, Papa S, Poscia R, Manzi G, Pascaretta A, et al. Right ventricular strain curve morphology and outcome in idiopathic pulmonary arterial hypertension. JACC Cardiovasc Imag janv 2021;14(1):162-72.

[44] Rudski LG, Lai WW, Afilalo J, Hua L, Handschumacher MD, Chandrasekaran K, et al. Guidelines for the echocardiographic assessment of the right heart in adults: a report from the American society of echocardiography. J Am Soc Echocardiogr juill 2010;23(7):685-713.

[45] Lai WW, Gauvreau K, Rivera ES, Saleeb S, Powell AJ, Geva T. Accuracy of guideline recommendations for two-dimensional quantification of the right ventricle by echocardiography. Int J Cardiovasc Imag oct 2008;24(7):691-8.

[46] Vonk M, Sander M, Vandenhoogen F, Vanriel P, Verheugt F, Vandijk A. Right ventricle Tei-index: a tool to increase the accuracy of non-invasive detection of pulmonary arterial hypertension in connective tissue diseases. Eur J Echocardiogr oct 2007;8(5):317-21.

[47] Peyrou J, Parsaï C, Chauvel C, Simon M, Dehant P, Abergel E. Echocardiographic assessment of right ventricular systolic function in a population of unselected patients before cardiac surgery: a multiparametric approach is necessary. Arch Cardiovasc Dis oct 2014;107(10):529-39. 